\title{
A Vaccinology Approach to the Identification and Characterization of Dermanyssus gallinae Candidate Protective Antigens for the Control of Poultry Red Mite Infestations
}

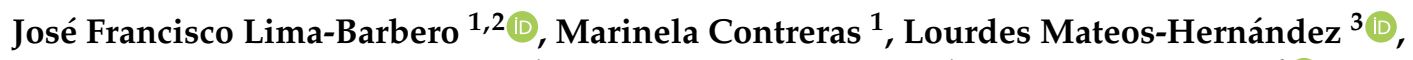 \\ Francisco Manuel Mata-Lorenzo ${ }^{1}$, Roxana Triguero-Ocaña ${ }^{1}$, Olivier Sparagano ${ }^{4}$ (D), \\ Robert D. Finn ${ }^{5,6} \mathbb{D}^{\mathrm{D}}$, Christina Strube ${ }^{7}$, Daniel R.G. Price ${ }^{8}$, Francesca Nunn ${ }^{8}$, Kathryn Bartley ${ }^{8}$, \\ Ursula Höfle $^{1}$, Mariana Boadella ${ }^{2}\left(\mathbb{D}\right.$, Alasdair J. Nisbet ${ }^{8}\left(\mathbb{D}\right.$, José de la Fuente ${ }^{1,9, * \mathbb{D}}$ and \\ Margarita Villar 1,10,*(D) \\ 1 SaBio. Instituto de Investigación en Recursos Cinegéticos, IREC (CSIC-UCLM-JCCM), Ronda de Toledo 12, \\ 13071 Ciudad Real, Spain; JoseFco.Lima@alu.uclm.es (J.F.L.-B.); Marinela.Contreras@uclm.es (M.C.); \\ fcomanuelmata@gmail.com (F.M.M.-L.); Roxana.Triguero@uclm.es (R.T.-O.); ursula.hofle@uclm.es (U.H.) \\ 2 Sabiotec, S.A. Ed., Polivalente UCLM, Camino de Moledores, 13005 Ciudad Real, Spain; mariana@sabiotec.es \\ 3 UMR BIPAR, INRA, Ecole Nationale Vétérinaire d'Alfort, ANSES, Université Paris-Est, 94700 \\ Maisons-Alfort, France; lourdes.mateos@vet-alfort.fr \\ 4 Department of Infectious Diseases and Public Health, City University of Hong Kong, Kowloon, Hong Kong \\ SAR, China; Olivier.sparagano@cityu.edu.hk \\ 5 Department of Applied Sciences, Faculty of Health \& Life Sciences, Northumbria University, Newcastle \\ Upon Tyne NE1 8ST, UK; RFinn@sgu.edu \\ 6 St George's International School of Medicine, Keith B. Taylor Global Scholars Program, Northumbria \\ University, Newcastle NE1 8ST, UK \\ 7 Institute for Parasitology, Centre for Infection Medicine, University of Veterinary Medicine Hannover, \\ 30559 Hannover, Germany; Christina.Strube@tiho-hannover.de \\ 8 Moredun Research Institute, Pentlands Science Park, Bush Loan, Edinburgh, Midlothian EH26 0PZ, UK; \\ Dan.Price@moredun.ac.uk (D.R.G.P.); francesca.nunn@moredun.ac.uk (F.N.); \\ kathryn.bartley@moredun.ac.uk (K.B.); alasdair.nisbet@moredun.ac.uk (A.J.N.) \\ 9 Department of Veterinary Pathobiology, Center for Veterinary Health Sciences, Oklahoma State University, \\ Stillwater, OK 74078-2007 USA \\ 10 Biochemistry Section, Faculty of Science and Chemical Technologies, and Regional Centre for Biomedical \\ Research [CRIB], University of Castilla-La Mancha, 13071 Ciudad Real, Spain \\ * Correspondence: jose_delafuente@yahoo.com (J.F.); margaritam.villar@uclm.es (M.V.)
}

Received: 9 October 2019; Accepted: 15 November 2019; Published: 20 November 2019 updates

\begin{abstract}
The poultry red mite (PRM), Dermanyssus gallinae, is a hematophagous ectoparasite considered as the major pest in the egg-laying industry. Its pesticide-based control is only partially successful and requires the development of new control interventions such as vaccines. In this study, we follow a vaccinology approach to identify PRM candidate protective antigens. Based on proteomic data from fed and unfed nymph and adult mites, we selected a novel PRM protein, calumenin (Deg-CALU), which is tested as a vaccine candidate on an on-hen trial. Rhipicephalus microplus Subolesin (Rhm-SUB) was chosen as a positive control. Deg-CALU and Rhm-SUB reduced the mite oviposition by 35 and $44 \%$, respectively. These results support Deg-CALU and Rhm-SUB as candidate protective antigens for the PRM control.
\end{abstract}

Keywords: Dermanyssus; poultry red mite; proteomics; vaccine; vaccinology; control; protective antigens 


\section{Introduction}

The parasitic mite Dermanyssus gallinae (Mesostigmata: Dermanyssidae), also known as poultry red mite (PRM), is the major pest for the poultry industry [1]. It is distributed worldwide, present in every production system and can be shown in high prevalence in commercial egg laying facilities, as is the case in Europe, reaching a prevalence of $100 \%$ in some countries [2]. The mite feeds on the blood of the hens in the dark and spends just 30-60 min on the host [3]; during daytime it hides in cracks out of the reach of the birds [4]. According to this behaviour, PRM can be better considered as a micro predator [5]. Dermanyssus gallinae requires a blood meal for moulting from protonymph to deutonymph, to adult and for egg-laying [6]. The PRM has severe effects on hens' health and welfare as its presence is related to anaemia and stress. Depending on the level of infestation, it can lead to increased mortality by exsanguination and behavioural disorders due to sleep deprivation [7-9]. Besides, PRM can act as a vector for several pathogenic viruses and bacteria $[10,11]$. The threat for the industry relies on the economic losses caused by the PRM in two ways: reduction of egg production associated with a negative impact on feed conversion ratio and a higher proportion of blood-spotted and low-quality eggs, which are downgraded and, secondly, cost-derived from pest control actions [12]. A recent estimate has set the losses caused by the PRM, only in the European Union, at €231 million [13].

One of the biggest challenges facing the egg industry is the control of the PRM. Chemical treatments have traditionally been used to control PRM, however, there is a limited number of acaricides authorised to treat mite infestations by European or national legislation. In addition, the development of resistance reduces the efficiency of the commonly used acaricides [2,14]. Recent research is focused on exploring different tools for alternative control of poultry red mite as biological control, plant-derived products, entomopathogenic fungi or physical control [2].

Vaccine development is a novel, environmentally friendly and promising method for PRM control. Some advantages of vaccination are the reduction of the use of pesticides, no contamination of the environment and animal products and unlikely development of resistance by the parasites [15]. Vaccination implies the identification of proteins that can act as vaccine antigens [16]. Recombinant proteins have been used to immunise host animals against parasitic species. A recombinant form of Bm86 is part of commercial vaccines that can protect cattle from Boophilus microplus tick infestations [17]. The limits to vaccine development are partly because of limited information about constituent proteins of Dermanyssus gallinae [18,19]. The publication of the transcriptome [20] and, more recently, the PRM genome [21] is expected to enhance protein identification with immunisation purposes. Proteins such as the tick Subolesin, the ortholog of the akirin present in insects and vertebrates, have shown a reducing effect on infestations by several ectoparasites, PRM amongst them [15,22].

In this work, we analyzed for the first time the proteomes of fed and unfed D. gallinae adults and nymphs. Quantitative proteomics analysis led to the identification of differentially represented proteins between different development stages and feeding status that could be putative protective antigens against D. gallinae. The efficacy of a candidate antigen was tested through an experimental infestation of vaccinated and naïve hens.

\section{Materials and Methods}

\subsection{Mite Collection and Proteins Extraction}

D. gallinae were collected, and proteins were extracted as previously described [23]. Briefly, mites collected from a free-range poultry unit in North Eastern England were distributed in four groups: engorged female adult mites (FA), non-fed female adult mites (UA), engorged proto- and deutonymphs (FN), and unfed proto- and deutonymphs (UN). For protein extraction, each group of mites were resuspended in ice-cold PBS supplemented with cOmplete Protease Inhibitor Cocktail (Roche Diagnostics GmbH, Mannheim, Germany) and homogenised on ice for two pulses of $30 \mathrm{~s}$ each with Ultra Turrex ${ }^{\circledR}$ T 25 D-S2 with a S25N-8G dispersing element (IKA, Sataufen, Germany). Samples were centrifuged at $5000 \times g$ for $20 \mathrm{~min}$ at $4{ }^{\circ} \mathrm{C}$ to remove insoluble material and debris. Protein 
concentration in the soluble phase was determined using the BCA Protein Assay (Thermo Scientific, San Jose, CA, USA) with bovine serum albumin as standard and protein samples were snap-frozen and stored at $-80^{\circ} \mathrm{C}$ until proteomics analysis.

\subsection{Proteomics Data Acquisition and Analysis}

Protein extracts from the four groups of mites (75 $\mu$ g per sample) were in-gel concentrated, as previously described [24]. After visualization of the unseparated protein bands by GelCode Blue Stain Reagent (Thermo Scientific), bands were excised and digested overnight at $37{ }^{\circ} \mathrm{C}$ with $60 \mathrm{ng} / \mu \mathrm{L}$ sequencing grade trypsin (Promega, Madison, WI, USA) at 5:1 protein:trypsin (w/w) ratio in $50 \mathrm{mM}$ ammonium bicarbonate $\mathrm{pH} 8.8$, containing $10 \%$ acetonitrile (v/v) [25]. The resulting tryptic peptides were extracted with $12 \mathrm{mM}$ ammonium bicarbonate $\mathrm{pH}$ 8.8, and digestion was stopped adding trifluoroacetic acid to a final concentration of $1 \%$. Peptides were desalted onto OMIX Pipette tips C18 (Agilent Technologies, Santa Clara, CA, USA), dried-down and stored at $-20{ }^{\circ} \mathrm{C}$ until mass spectrometry analysis.

The desalted protein digests were resuspended in $0.1 \%$ formic acid and analyzed by reverse-phase liquid chromatography coupled to mass spectrometry (RP-LC-MS/MS) using an Easy-nLC II system coupled to an LTQ-Orbitrap-Velos-Pro mass spectrometer (Thermo Scientific) as previously described [24]. Briefly, after on-line concentration of peptides by RP using a $0.1 \times 20 \mathrm{~mm} \mathrm{C18}$ $\mathrm{RP}$ precolumn (Thermo Scientific), peptides were separated in a $0.075 \times 250 \mathrm{~mm}$ C18 RP column (Thermo Scientific) operating at $300 \mathrm{~nL} / \mathrm{min}$ and eluted using a 140-min gradient from 5 to $40 \%$ solvent $\mathrm{B}$ in solvent A (solvent A: $0.1 \%$ formic acid in water; solvent B: $0.1 \%$ formic acid in acetonitrile). ESI ionisation was done using a Nano-bore Stainless Steel emitter ID $30 \mu \mathrm{m}$ (Thermo Scientific) interface. Peptides were detected in survey scans from 400 to $1600 \mathrm{amu}(1 \mu \mathrm{scan})$, followed by 20 data-dependent MS/MS scans (Top 20), using an isolation width of 2 mass-to-charge ratio units, normalised collision energy of $35 \%$, and dynamic exclusion applied during 30 s periods.

The MS/MS raw files were searched against a compiled database containing the UniProt Parasitiformes and Gallus gallus proteome databases (141,928 and 29,484 entries in April 2018, respectively) (http://www.uniprot.org) together with a database created from the predicted secretome and transmembrane proteins of D. gallinae (10,454 entries) [26], using the SEQUEST algorithm (Proteome Discoverer 1.4, Thermo Scientific). The constraints imposed for the search were: tryptic cleavage after Arg and Lys, two maximum missed cleavages, tolerances of $20 \mathrm{ppm}$ and 0.05 Da for precursor and MS/MS fragment ions, respectively, and Met oxidation and Cys carbamidomethylation as variable modifications. Searches were also performed against a decoy database in an integrated decoy approach. A false discovery rate (FDR) $<0.01$ was considered as a condition for successful peptide assignments and at least two peptide-spectrum matches (PSMs) per protein in at least one of the samples analyzed were the necessary condition for protein identification. Three biological replicates were used for each of the four groups of PRM analyzed (fed and unfed adults and nymphs). Raw proteomics data are available through the PeptideAtlas repository (http://www.peptideatlas.org) with the dataset identifier PASS01346.

Gene ontology (GO) analysis of biological process (BP), molecular function (MF) and cellular component (CC) was conducted using Blast2GO software (version 3.0; www.blast2go.com) and manually completed using QuickGO databases (https://www.ebi.ac.uk/QuickGO/). To show proteins distribution amongst the four groups, a Venn's diagram was constructed using InteractiveVenn (http://www.interactivenn.net/) [27].

\subsection{Criteria for Selection of Candidate Protective Antigens}

The selection of candidate protective antigens to be tested was based on differentially over-represented proteins in adult female versus nymph mites of the same feeding status and/or differentially over-represented proteins in fed versus unfed mites in the same developmental stage, since these proteins are potentially good candidates to be used as antigens to block mites development. 
For quantitative analysis of PRM proteins, after discarding host proteins, the total number of PSMs for each PRM protein was normalised against the total number of PSMs in PRM samples and compared between groups using a paired comparison Chi ${ }^{2}$-test $\left(\chi^{2}\right)(p<0.05)$ in $\mathrm{R}$ software [28] (Table 1). After discarding differentially represented proteins that had been tested before as vaccine candidates: vitellogenin and cathepsin [18], tropomyosin and paramyosin [29] and histamine release factor [30]; proteins identified in a database from secreted and transmembrane D. gallinae proteins were selected to favour antibody-antigen interactions in mites feeding on vaccinated hens. Of the potential candidates, only calumenin fulfilled the criteria and was selected to be tested as a protective antigen. Calumenin isoform 2 coding sequence (isotig18930) was obtained from the published predicted secretome and transmembranome of D. gallinae [26]. As a vaccination positive control, Subolesin from Rhipicephalus microplus (Rhm-SUB) [22].

Table 1. Differentially Represented Proteins Associated with Feeding and Developmental Status.

\begin{tabular}{|c|c|c|c|c|}
\hline Accession No. ${ }^{a}$ & Description & $\begin{array}{c}\text { Fold } \\
\text { Change }\end{array}$ & $\underset{p \text {-Value }}{\chi^{2}}$ & Significance $^{c}$ \\
\hline \multirow{2}{*}{ isotig10396 } & \multirow{2}{*}{ Peptidyl-prolyl cis-trans isomerase } & $\infty$ & 0.040 & FA vs. UA \\
\hline & & 0 & 0.025 & UA vs. UN \\
\hline \multirow{2}{*}{ isotig11213 } & \multirow{2}{*}{ Vitellogenin 2} & 1.54 & 0.000 & FN vs. UN \\
\hline & & 1.44 & 0.001 & UA vs. UN \\
\hline \multirow{2}{*}{ isotig15430 } & \multirow{2}{*}{ Vitellogenin 2} & 1.63 & 0.014 & FA vs. FN \\
\hline & & 1.36 & 0.037 & UA vs. UN \\
\hline \multirow{3}{*}{ A0A0M4FBG8 } & \multirow{3}{*}{ Vitellogenin 1 (D. gallinae) } & 1.65 & 0.000 & FN vs. UN \\
\hline & & 0.70 & 0.006 & FA vs. FN \\
\hline & & 0.38 & 0.019 & FA vs. FN \\
\hline \multirow[t]{2}{*}{ S5GFP7 } & \multirow[t]{2}{*}{ Vitellogenin 2 (Neoseiulus cucumeris) } & 4.20 & 0.002 & FN vs. UN \\
\hline & & 3.00 & 0.027 & UA vs. UN \\
\hline B5B8U1 & Histamine release factor (D. gallinae) & 0.29 & 0.020 & FN vs. UN \\
\hline \multirow{2}{*}{ A0A131Y6P3 } & \multirow{2}{*}{ Ribosomal protein s7 (Ixodes ricinus) } & 0.27 & 0.031 & FN vs. UN \\
\hline & & 0.18 & 0.012 & UA vs. UN \\
\hline A0A023GGI9 & $\begin{array}{l}\text { Chromatin remodeling complex rsc subunit } \\
\text { rsc1/polybromo (Amblyomma triste) }\end{array}$ & $\infty$ & 0.044 & FN vs. UN \\
\hline A0A1R3S3F0 & Paramyosin (D. gallinae) & 0.45 & 0.018 & FA vs. FN \\
\hline Q2WBI0 & Tropomyosin (D. gallinae) & 0.35 & 0.026 & FA vs. FN \\
\hline isotig21684 & Cathepsin 1 precursor & 0.29 & 0.017 & UA vs. UN \\
\hline isotig16123 & Cathepsin 1 & 0.22 & 0.033 & UA vs. UN \\
\hline isotig20927 & Cathepsin 1 & 0 & 0.024 & UA vs. UN \\
\hline isotig21530 & Cathepsin l-like & 0 & 0.014 & UA vs. UN \\
\hline isotig21385 & Cathepsin s-like & 0 & 0.004 & UA vs. UN \\
\hline \multirow{2}{*}{ isotig18930 } & \multirow{2}{*}{ Calumenin isoform 2} & 3.33 & 0.047 & FA vs. FN \\
\hline & & 3.67 & 0.035 & UA vs. UN \\
\hline isotig12641 & Protein npc2-like protein & 0.27 & 0.031 & UA vs. UN \\
\hline \multirow{2}{*}{ isotig11090 } & \multirow{2}{*}{ Chymotrypsin b-like } & 0 & 0.049 & FA vs. FN \\
\hline & & 0 & 0.014 & UA vs. UN \\
\hline isotig21611 & Cytotoxin-like protein & 0 & 0.027 & FA vs. FN \\
\hline V5HC54 & Beta-spectrin (I. ricinus) & 3.33 & 0.047 & FA vs. FN \\
\hline A0A131XHW1 & Beta-spectrin (Hyalomma excavatum) & 3.33 & 0.047 & FA vs. FN \\
\hline isotig18820 & Deoxyribonuclease II & $\infty$ & 0.007 & FA vs. FN \\
\hline A0A131Y3B8 & Uncharacterized protein (I. ricinus) & 19.00 & 0.000 & FA vs. FN \\
\hline \multirow{2}{*}{ A0A1E1X6V0 } & \multirow{2}{*}{ Conserved plasma membrane protein (A. aureolatum) } & 3.25 & 0.025 & FA vs. FN \\
\hline & & 6.50 & 0.005 & UA vs. UN \\
\hline isotig08662 & PREDICTED: uncharacterized protein LOC100908559 & 0.22 & 0.033 & UA vs. UN \\
\hline isotig13475 & PREDICTED: uncharacterized protein LOC100900008 & 0 & 0.027 & FA vs. FN \\
\hline
\end{tabular}

\subsection{Cloning of Antigens and Production of Recombinant Proteins}

Recombinant Rhipicephalus microplus Subolesin (Rhm-SUB), with GenBank accession number GQ456170 was expressed and purified as reported previously [31]. D. gallinae calumenin (Deg-CALU) (GenBank accession number BK011287) cDNA was amplified from a synthetic gene optimised for codon usage in E. coli (GenScript, Hong Kong) using oligonucleotide primers Deg-CALU-F: 5' CACCATGGATAACTACGTCGATCAG and Deg-CALU-R: 5' - GAGTTCGCTGTGCTGGCCGA. The 
DNA coding sequence was cloned in the expression vector pET101, expressed in E. coli strain BL21 as previously described [32]. Transformed E. coli strains were induced with isopropyl $\beta$-D-1-thiogalactopyranoside (IPTG) for $4.5 \mathrm{~h}$ to produce recombinant proteins, which using this expression system were fused to Histidine tags for purification by affinity to Ni using $1 \mathrm{~mL}$ HisTrap FF columns mounted on an AKTA-FPLC system (GE Healthcare, Piscataway, NJ, USA) in the presence of $7 \mathrm{M}$ urea lysis buffer [32] and were purified to $>95 \%$ of total cell.

\subsection{Sequence Analysis for Deg-CALU}

Calumenin coverage of identification by RP-LC-MS/MS was investigated. Analysis of protein sequence identity for Deg-CALU was conducted using the Blastp tool from BLAST (https://blast.ncbi. nlm.nih.gov/Blast.cgi).

\subsection{Vaccine Formulations}

The purified denatured recombinant proteins were refolded by dialysis against 1000 volumes of PBS (137 mM NaCl, $\left.2.7 \mathrm{mM} \mathrm{KCl}, 10 \mathrm{mM} \mathrm{Na}_{2} \mathrm{HPO}_{4}, 1.8 \mathrm{mM} \mathrm{KH} \mathrm{PO}_{4}\right)$, pH 7.4 for $12 \mathrm{~h}$ at $4{ }^{\circ} \mathrm{C}$. Recombinant proteins were then concentrated using an Amicon Ultra-15 ultrafiltration device (cut off $10 \mathrm{KDa}$ ) (Millipore-Merck, Darmstadt, Germany), adjusted to $0.5 \mathrm{mg} / \mathrm{mL}$. For vaccine formulation, recombinant Rhm-SUB and Deg-CALU proteins or saline control were adjuvanted in Montanide ISA 71 VG (Seppic, Paris, France) $[33,34]$.

\subsection{Hen Vaccination and PRM Infestation}

Three experimental groups (Rhm-SUB, Deg-CALU and Control) with 5 Lohmann Brown 20 weeks old hens each were randomly assigned. One hen in the control group was humanely euthanized on day 28 due to health problems not related to the experiment. Hens were vaccinated on day 0 (V1) and 14 (V2) with a $0.4 \mathrm{~mL}$ intramuscular injection in the breast muscle. Total vaccine doses were $20 \mu \mathrm{g}$ and $40 \mu \mathrm{g}, \mathrm{V} 1$ and V2 respectively, for Deg-CALU and $45 \mu \mathrm{g}$ for both vaccinations of Rhm-SUB. The study was terminated on day 42.

An on-hen feeding device [35] was used to evaluate vaccine efficiency. Briefly, the device consists of a pouch made from flexible $105 \mu \mathrm{m}$ aperture width polyester mesh, containing approximately 100 starved adult female D. gallinae mites. Mites were starved for 1 week at room temperature and 3 weeks at $4{ }^{\circ} \mathrm{C}$ and were placed in the feeding devices and attached for $3 \mathrm{~h}$ to the defeathered thigh of each hen using a small amount of medical tape (Leucoplast, BSN Medical, Germany) and secured with a medical bandage (Henry Schein Inc., New York, EEUU). Feeding assays were conducted three times (replicates), at days 28, 30 and 32 post V1 [34]. Every hen was included in each replicate.

\subsection{Vaccine Efficacy}

Mites were identified as fed when they were engorged and bright red. They were considered dead if they did not show any movement and were unresponsive to touch stimulus. Engorged mites were collected from the pouches and transferred into individual wells of a 96-well tissue culture plate (Costar, Corning, NY, USA) and sealed with AeraSeal film (Sigma-Aldrich, St. Louis, USA; A9224-50EA). Plates were placed into an incubator $\left(25^{\circ} \mathrm{C}\right.$ and $85 \%$ relative humidity) and checked every $24 \mathrm{~h}$ for five days and on day 7 after feeding. Feeding rate was recorded when transferring from the pouch to the plates. Mite mortality, laying mites, oviposition, egg hatchability and larval development were recorded in every check to assess the vaccine efficacy. 


\subsection{Analysis of Hen IgY Antibody Response by ELISA}

Blood samples were collected from each hen before each vaccination (day 0 and 14), during feeding assays (day 28) and at the end of the experiment. Whole blood was obtained by venipuncture of the cutaneous ulnar vein. Serum was recovered following clotting at $4{ }^{\circ} \mathrm{C}$ for $24 \mathrm{~h}$ and centrifugation at $3000 \mathrm{~g}$ and stored at $-20^{\circ} \mathrm{C}$ for further analysis.

Two indirect ELISA tests were performed based on previously described protocols [36] to detect IgY antibodies against both antigens in serum samples from vaccinated and control hens. One was performed to evaluate the trend on the antibody level during the whole experiment and another to compare the level of antibodies and the mite oviposition at the moment of experimental infestation. Briefly, high absorption capacity polystyrene microtiter 96 -well plates were coated overnight at $4{ }^{\circ} \mathrm{C}$ with $0.5 \mu \mathrm{g} /$ well of each recombinant protein diluted to $10 \mu \mathrm{g} / \mathrm{mL}$ with coating buffer ( $50 \mathrm{mM}$ sodium bicarbonate, $\mathrm{pH}$ 9.6). ELISA plates were washed six times with $200 \mu \mathrm{L}$ PBST (PBS containing $0.05 \% \mathrm{v} / \mathrm{v}$ Tween-20) and blocked with $200 \mu \mathrm{L} /$ well of blocking buffer $(10 \% \mathrm{w} / \mathrm{v})$ powdered soy milk in TBST buffer ( $50 \mathrm{mM}$ Tris, $150 \mathrm{mM} \mathrm{NaCl}, 0.05 \% \mathrm{v} / \mathrm{v}$ Tween-20) for $2 \mathrm{~h}$ at room temperature on shaker. Sera from the vaccinated hens were used as primary antibodies. $50 \mu \mathrm{L} /$ well of the primary antibodies were used at a 1/1600 (Rhm-SUB and pooled control group) or 1/800 (Deg-CALU) dilution in TBST. For the analysis of the antibody level temporal trends ELISA, the serum samples obtained from the control group were pooled together. Three replicas for each serum sample were tested. After a 1-hour incubation at room temperature, plates were washed and $50 \mu \mathrm{L} /$ well of rabbit anti-IgY-peroxidase conjugate (Sigma-Aldrich, St. Louis, USA), diluted 1/30,000 in TBST, were added. After six washes with washing solution, $50 \mu \mathrm{L} /$ well of substrate solution (Fast OPD, Sigma-Aldrich, St. Louis, USA) was added. Finally, the reaction was stopped after 20 mins with $25 \mu \mathrm{L} /$ well of $2.5 \mathrm{mM} \mathrm{H}_{2} \mathrm{SO}_{4}$, and the and the optical density (OD) was measured at $450 \mathrm{~nm}$ using ELx808IU Ultra Microplate Reader (Bio-Tek Instruments, UK).

Western blot analysis was conducted as previously described [32]. Briefly, $10 \mu \mathrm{g}$ of each recombinant antigen per lane were separated by electrophoresis on $12 \%$ Bis-Tris Novex gels in NuPAGEßMES SDS Running Buffer (GE Healthcare, UK). Proteins were transferred to nitrocellulose membrane using a Xcell II blot module (GE Healthcare, UK), following the manufacturer's instructions. Individual lanes of the membrane were excised and blocked by incubation in $5 \% \mathrm{w} / \mathrm{v}$ dried skimmed milk in PBST at $4{ }^{\circ} \mathrm{C}$ for $12 \mathrm{~h}$ and washed in PBST afterwards. Sera from each vaccination group of day 28 post-vaccination were used as primary antibodies, sera from the same vaccination group but of day 0 were used as negative controls. Sera were diluted 1/100 in PBS and incubated for two hours at RT. The membrane was washed and incubated in rabbit anti-IgY-peroxidase conjugate (Sigma-Aldrich, St. Louis, USA), diluted 1/30,000 in PBS for $1 \mathrm{~h}$ at RT, followed by washing and colorimetric development with SIGMAFAST ${ }^{\text {TM }}$ 3.3'-DAB (Sigma-Aldrich, St. Louis, USA).

\subsection{Statistical Analysis}

Antibody levels between vaccinated and control groups were compared by Mann-Whitney U test $(p<0.05)$ using SPSS (IBM ${ }^{\circledR}$ SPSS $^{\circledR}$ Statistics $\left.{ }^{\circledR} v 23\right)$. Nymphs and dead or missing mites were removed from the analysis for the effects on reproduction.

A generalized linear mixed model (GLMM) was performed to determine the group differences based on a Negative Binomial distribution and log as link function. The model included the total number of eggs laid per individual mite (oviposition) as the dependent variable. The treatment group was included as a fixed effect and hen number and assay replicate as random factors. For this analysis SPSS (IBM ${ }^{\circledR}$ SPSS ${ }^{\circledR}$ Statistics ${ }^{\circledR}$ v23) software was used. 


\subsection{Ethics Approval}

The experiment using hens was conducted under the regulations of a UK Home Office Project Licence; the experimental design was ratified by the Experiments and Ethics Committee of the Moredun Research Institute (MRI), UK.

\section{Results and Discussion}

Vaccine development is a promising tool for the control of D. gallinae. However, limited knowledge is available about its proteome. Omics tools have provided new databases to allow the identification of PRM proteins and probable antigens $[20,26]$. To our knowledge, this is the first work that characterize the proteomes of fed and unfed D. gallinae adults and nymphs.

\subsection{Proteomics Analysis of D. gallinae Development Stages and Feeding Status}

After proteomics analysis of PRM samples, as described in Materials and Methods, a total of 1322 PRM and 627 host proteins were identified, respectively (Supplementary Table S1). The number of identified proteins varied between experimental groups (fed adults (FA), unfed adults (UA), fed nymphs (FN) and unfed nymphs (UN)) ranging from 673 to 787 and from 304 to 414 for PRM and host proteins, respectively (Figure 1A). As expected, the proportion of host proteins present in mites increased with feeding and aging (Figure 1B). The same PRM proteins were shared in several experimental groups with 339 proteins found in all groups and 131, 142, 111 and 162 proteins that were identified exclusively in FA, UA, FN and UN, respectively (Figure 1C).
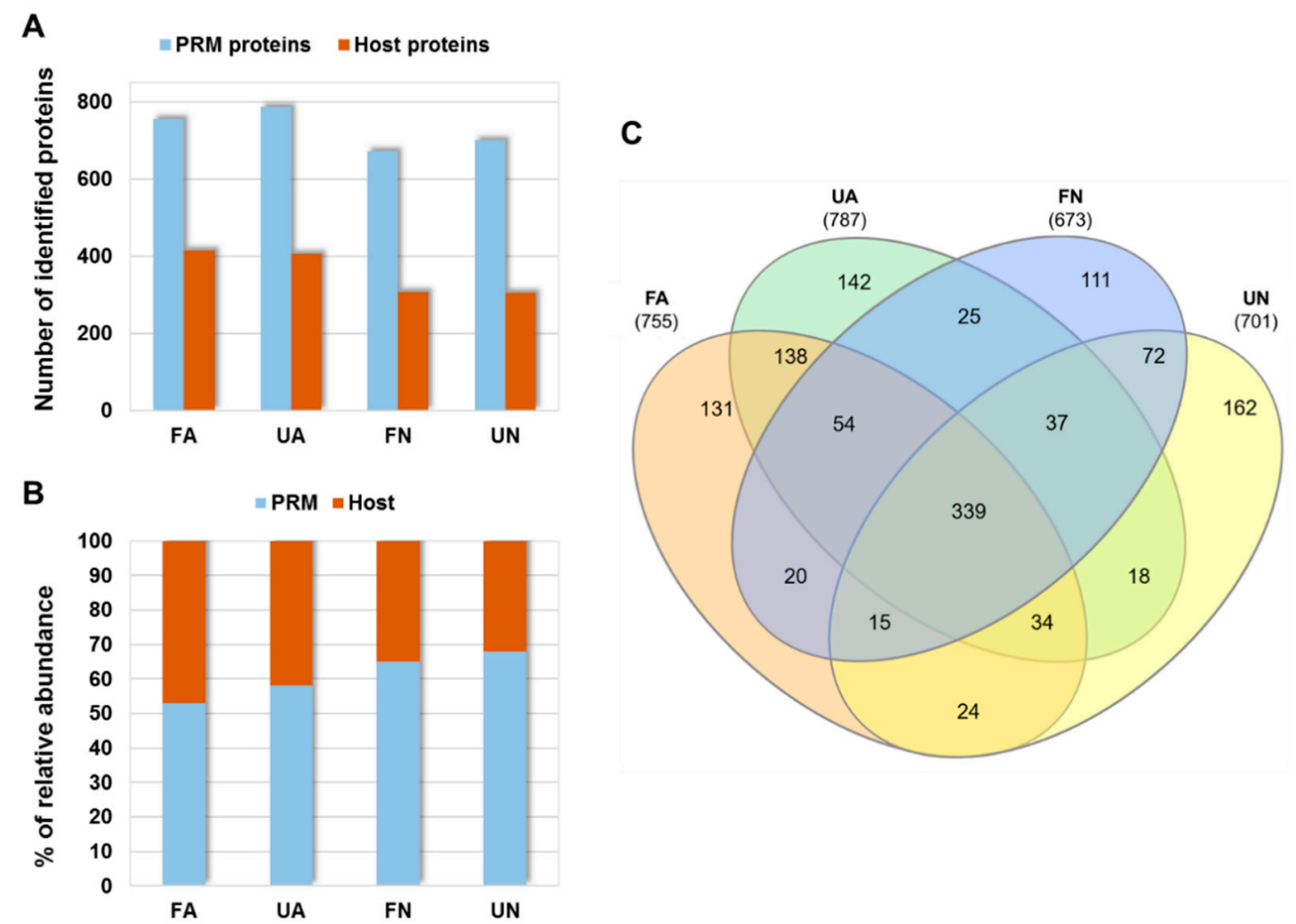

Figure 1. Proteomics results in PRM. (A) Proteins were identified with FDR $<0.01$ and at least two PSMs per protein in at least one of the analyzed samples. (B) Percentage of relative abundance for PRM and host proteins calculated with respect to the total number of PSMs detected in each sample group. (C) Venn diagram showing PRM protein distribution between different groups analyzed. FA: engorged female adult mites, UA: non-fed female adult mites, FN: engorged proto- and deutonymphs, UN: unfed proto- and deutonymphs. 
From the PRM protein identified, 17\% were proteins assigned to D. gallinae, whereas the rest of proteins were mainly assigned to Ixodes, Amblyomma and Rhipicephalus spp. (30\%, 25\% and 17\%, respectively) (Figure 2A). These results indicating a high degree of homology between D. gallinae and tick proteins and a good quality of the data obtained because only the $6 \%$ of protein sequences present in the database constructed for searching belonged to D. gallinae (10,602 entries from a total of 181,866 entries). Moreover, data confirm the validity of the predicted secretome and transmembranome of D. gallinae [26] since the $91 \%$ of the D. gallinae assigned proteins match to entries from this database (204 of 224 D. gallinae proteins) (Figure 2A). Regarding host proteins, haemoglobins were the most abundant proteins identified, representing 21\%, 19\%, 33\% and 26\% of the total of host PMSs detected in FA, UA, FN and UN, respectively (Figure 2B). Host heat shock proteins were identified constituting around $5 \%$ of the total host proteins identified indicating the hens stress response as result of the mite bite (Figure 2B).

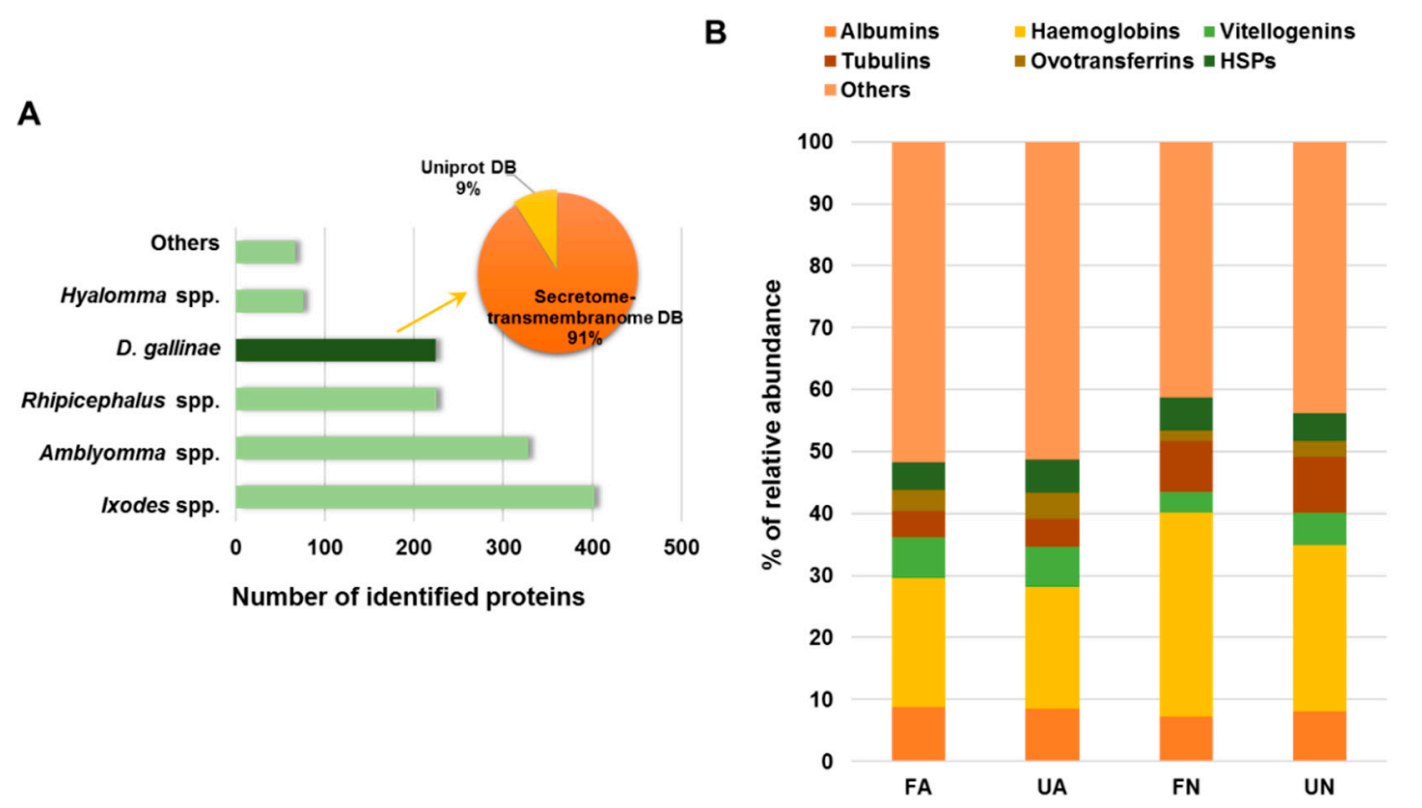

Figure 2. Distribution of PRM and host proteins identified. (A) Database assignation distribution of PRM proteins. (B) Percent distribution of host proteins calculated with respect to the total number of host PSMs detected in each sample group. FA: engorged female adult mites, UA: non-fed female adult mites, FN: engorged proto- and deutonymphs, UN: unfed proto- and deutonymphs.

\subsection{Functional Analysis of Identified Proteins in D. gallinae Development Stages and Feeding Status}

PRM proteins identified were functionally annotated using Blast2GO software and manual search. Blast2GO search revealed 392 successful protein annotations and manual GO search offered 594 additional annotations. To compare between development stages, proteins identified in fed and unfed female adults, and in fed and unfed nymphs, were grouped in adults and nymphs groups, respectively. To compare the feeding status of mites, proteins identified in fed female adults and fed nymphs, and in unfed female adults and unfed nymphs were grouped in fed and unfed groups, respectively. GO annotations for proteins corresponding to each female adults, nymphs, fed and unfed groups were distributed according to Biological Process (BP) (Figure 3), Molecular Function (MF) (Figure 4A) and Cellular Component (CC) (Figure 4B). Most of the identified PRM proteins were involved in metabolic and cellular processes and biological regulation (Figure 3) participating in molecular functions related to binding or catalytic activity (Figure 4A). Regarding the cellular component, cell part, membrane, organelle and protein-containing complex were the most abundant localizations (Figure 4B). 


\section{Biological process}

= Metabolic process

- Cellular process

n Biological regulation

- Localization

- Response to stimulus

- Cellular com ponent

biogenesis
Signaling

-Biological adhesion

- Immune system process

- Reproduction

- Mulicellular organismal process
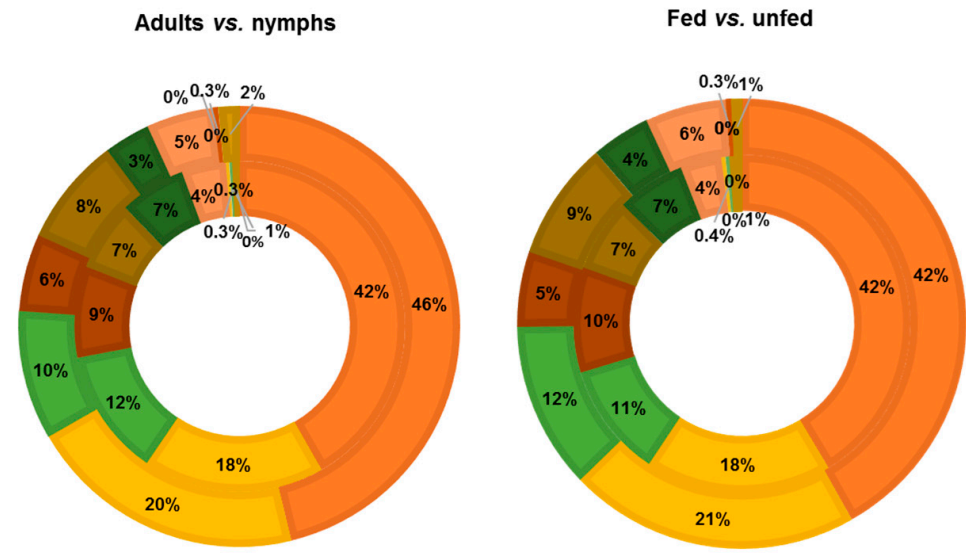

Figure 3. Biological process categorization of PRM proteins identified after proteomics analysis. Proteins were functionally annotated and grouped according to biological process using Blast2GO software and manual search. The same protein could have several GO annotations, a fact that was included in the results shown in the graphs. Left picture: Distribution of proteins identified in female adult PRM (inner circle) and nymph PRM (outer circle). Right picture: Distribution of proteins identified in fed PRM (inner circle) and unfed PRM (outer circle).

A

Molecular function
m Cataly tic activity
minding
- Structural molecule
activity
- Transporter activity
molecular transducer
activity
- Transcription
regulator activity
Regulation of
molecular function

B

\section{Cellular component}

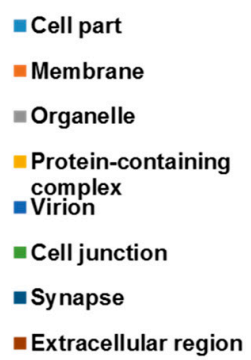

Adults vs. nymphs

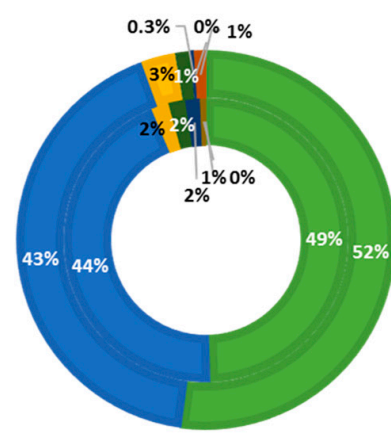

Adults vs. nymphs

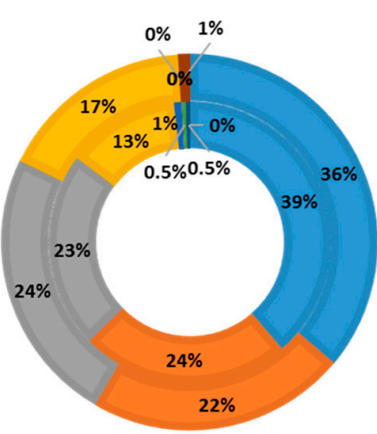

Fed vs. unfed

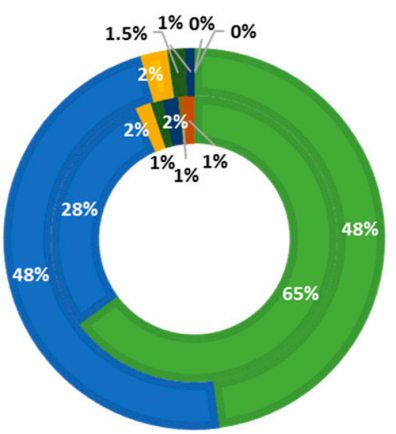

Fed vs. unfed

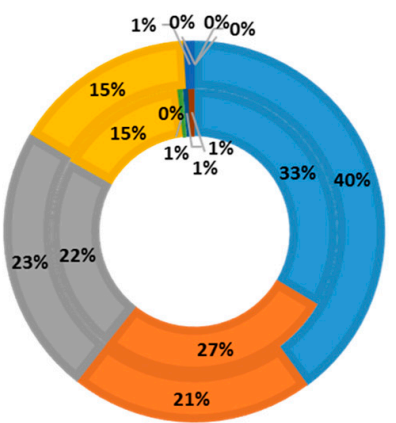

Figure 4. Molecular function and cellular component categorization of PRM proteins identified after proteomics analysis. Proteins were functionally annotated and grouped according to molecular function and cellular component using Blast2GO software and manual search. The same protein could have several GO annotations, a fact that was included in the results shown in the graphs. (A) Molecular function categorization. Left picture: Distribution of proteins identified in female adult PRM (inner circle) and nymph PRM (outer circle). Right picture: Distribution of proteins identified in fed PRM (inner circle) and unfed PRM (outer circle). (B) Cellular component categorization. Left picture: Distribution of proteins identified in female adult PRM (inner circle) and nymph PRM (outer circle). Right picture: Distribution of proteins identified in fed PRM (inner circle) and unfed PRM (outer circle). 
Although protein ontology distribution in the different groups was similar, several differences can be observed. Biological processes involved in localization and cellular component biogenesis were over-represented in adults mites with respect to nymphs and in fed with respect to unfed mites, whereas the response to stimulus and signalling were found under-represented (Figure 3). Catalytic activity was the molecular function most relevant in mites reaching its maximum representation in fed mites (65\%) where the value of binding was the lowest of the four groups (28\%) (Figure $4 \mathrm{~A})$. Around a quarter of the proteins identified were part of the membrane with greater representation in adults and fed mites, compared to nymphs and unfed mites (Figure 4B). Proteins corresponding to extracellular region were undetectable in adults and fed mites (Figure 4B).

To appreciate functional differences between the four groups of mites under study, the ontology of the proteins identified exclusively in each of the groups was analyzed (Figure 5). Within the two most abundant biological processes, unfed nymphs showed the most represented metabolic process whereas that fed nymphs highlighted in cellular processes (Figure 5A). Almost all the proteins exclusively detected in FN showed catalytic activity (91\%) and only this group showed regulation of molecular function (Figure 5B). Moreover, proteins of fed nymphs were those located mostly in membrane showing proteins corresponding to extracellular region (Figure 5C).
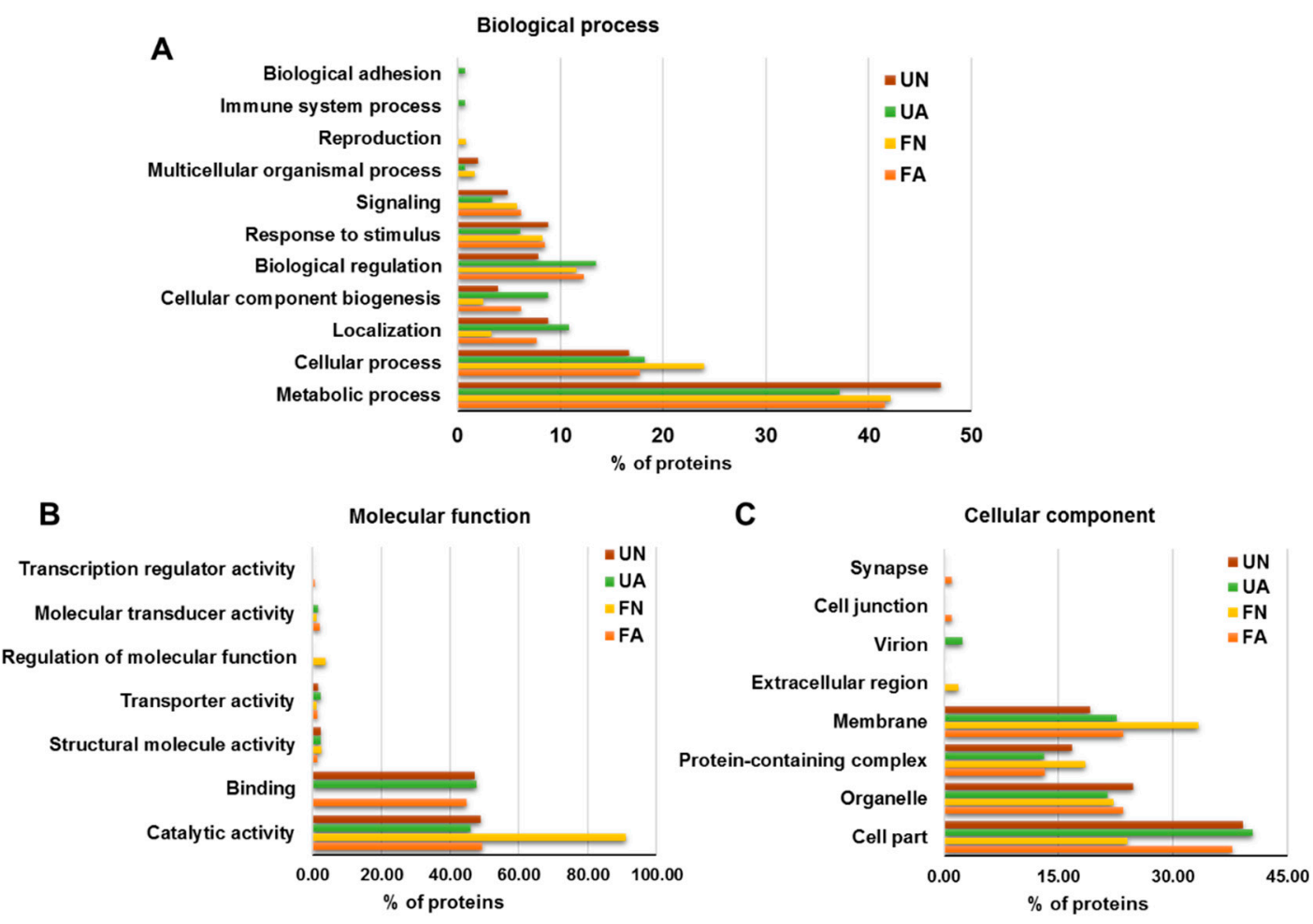

Figure 5. GO analysis of PRM proteins detected exclusively in each group analyzed. Proteomics analysis and DB search resulted in the identification of 131, 142, 111 and 162 proteins exclusively in FA, UA, FN and UN, respectively. These proteins were functionally annotated and grouped according to BP (A), MF (B) and CC (C) using Blast2GO software and manual search. The same protein could have several GO annotations, a fact that was included in the results shown in the graphs. FA: engorged female adult mites, UA: non-fed female adult mites, FN: engorged proto- and deutonymphs, UN: unfed proto- and deutonymphs.

\subsection{Characterization of PRM Candidate Protective Antigens}

From 1322 PRM proteins identified, 26 showed statistical differences between at least two groups after $\chi^{2}$-test $(p<0.05)$ (Table 1), fifteen of them identified in PRM secretome - transmembranome DB [26]. Related with feeding status, peptidyl-prolyl cis-trans isomerase were significantly over-represented in fed adults with respect to unfed adults, as were vitellogenins 1 and 2, and chromatin remodelling 
complex whereas histamine release factor and ribosomal protein s7 were under-represented, in fed $v s$. unfed nymphs (Table 1). The rest of the statistical differences were related with the developmental status (Table 1).

Several of the differentially represented proteins identified in this work had been tested before as vaccine candidates: vitellogenin and cathepsins [18], tropomyosin and paramyosin [29] and histamine release factor [30]. These proteins have been evaluated as vaccine candidates using the in-vitro feeding device. From the rest of proteins, only calumenin isoform 2 was over-represented in adults vs. nymphs, both in fed and unfed status, $\left(\chi^{2}, p=0.047\right.$ (AF vs. NF), $p=0.035$ (AU vs. NU)) and identified in the secretome - transmembranome DB. For this reason, Deg-CALU was selected as a candidate protective antigen together with Rhm-SUB as positive control due to its previously identified effects on mite mortality after feeding [22].

Deg-CALU protein coverage based in peptide identification from proteomics data was $34.8 \%$ (Figure 6A). Phylogenetic analysis revealed that Deg-CALU is taxonomically related to calumenin-like proteins from other Mesostigmata mite species (Figure 6B). Calumenin is located in membranes, amongst other subcellular compartments and participates in metabolic process and binding. This ontology is in concordance with the most abundant biological process and molecular function identified in PRM proteins (Figures 3 and 4).

A

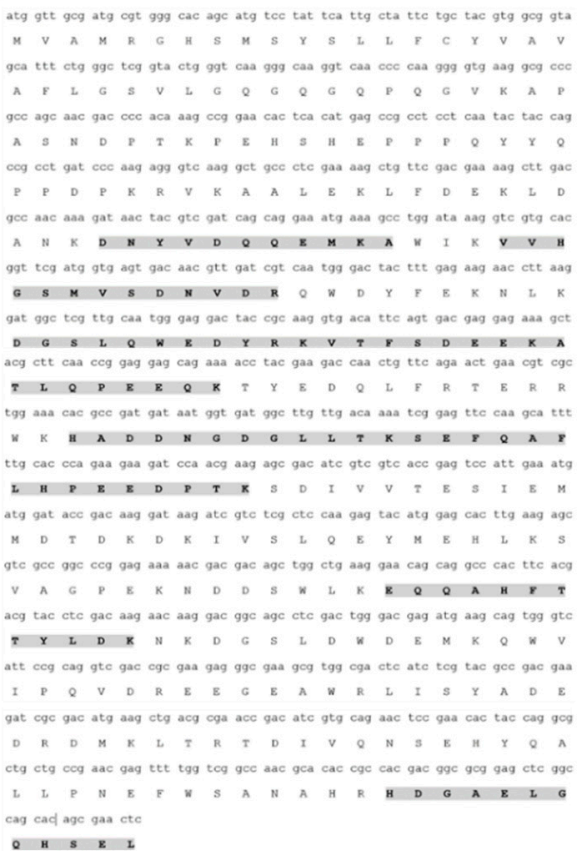

B

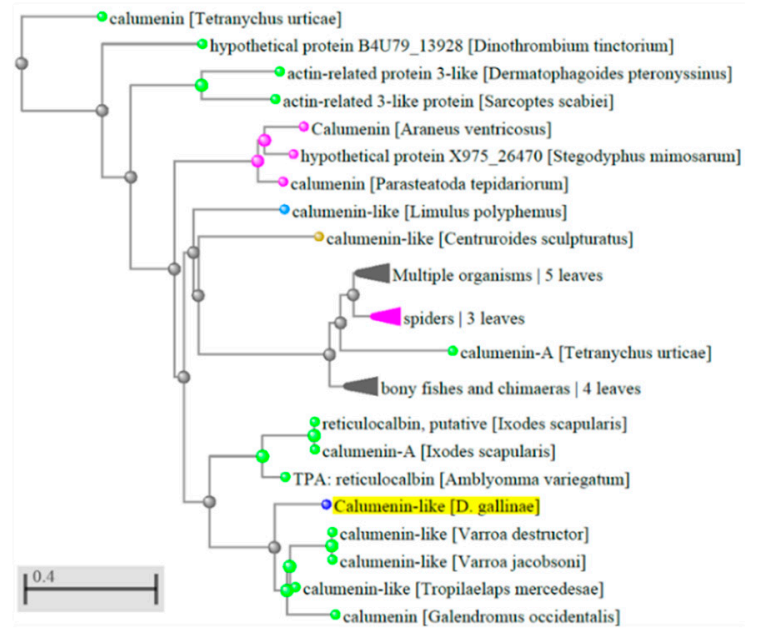

Figure 6. Deg-CALU protein coverage and phylogenetic analysis. (A) Calumenin isoform 2 coding sequence (isotig18930) [26]. Translated amino acid is shown with its corresponding nucleotide triplet. Peptides identified by RP-LC-MS/MS are marked (grey shadow). (B) Phylogenetic tree for Deg-CALU was constructed using the Blastp tool from BLAST (https://blast.ncbi.nlm.nih.gov/Blast.cgi).

\subsection{Immune Response to Vaccination}

Vaccination with Deg-CALU and Rhm-SUB triggered an antigen-specific IgY immune response in hens. Despite individual variation in the immune response for vaccinated hens was observed, the immune response of vaccinated hens was significantly higher than the control group (Mann-Whitney $\mathrm{U}$ test, $p<0.05)$. The serum IgY antibody response against Deg-CALU increased after immunization and remained higher than controls until the last bleeding ( 35 days after first immunisation) (Figures 7A and 8A). The first administration of Rhm-SUB vaccine showed no increase in the antibody level compared to the control group; it was necessary to administer a second dose on day 14 to stimulate 
the immune response, reaching its peak on day 28 (Figures $7 \mathrm{~B}$ and $8 \mathrm{C}$ ). This immune response to injected Subolesin is different from that observed by Harrington et al., 2009 [22], where two peaks in the antibody levels were observed. The difference in immune response to Subolesin between the current study and previous work might be attributable to one of these three differences in study design: the source of the Subolesin, the amount of injected antigen $(20 \mu \mathrm{g}$ first dose $/ 40 \mu \mathrm{g}$ second dose vs. 50 $\mu \mathrm{g}$ single dose), or the adjuvant used (Montanide ${ }^{\circledR}$ ISA 71 VG, a poultry adjuvant, vs. Montanide ${ }^{\circledR}$ ISA 50 V2, a livestock adjuvant). The serum recognition of Deg-CALU (Figure 7C) (37.7 kDa) and Rhm-SUB (Figure 7D) (18.7 kDa) by antigen-specific IgY present in the serum was also demonstrated by Western Blot. Serum anti-Rhm-SUB IgY also indicated the presence of Rhm-SUB multimers and some potential protein degradation products, a common effect with Akirin and Subolesin [22,37].

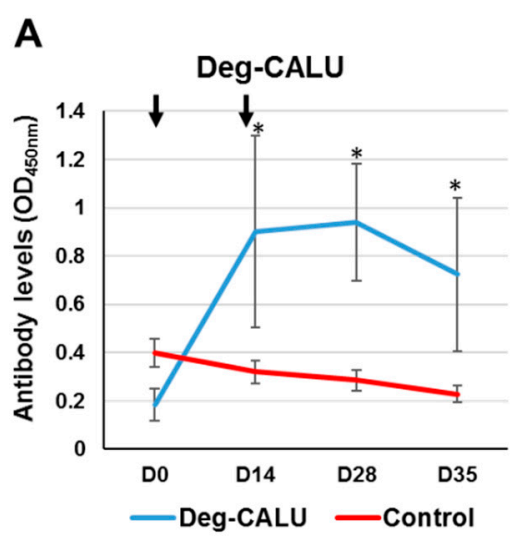

B

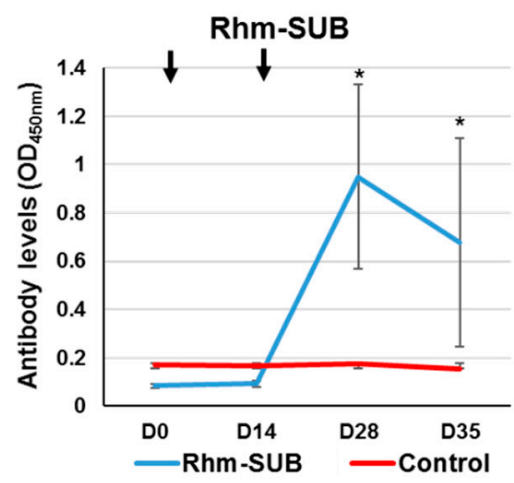

C

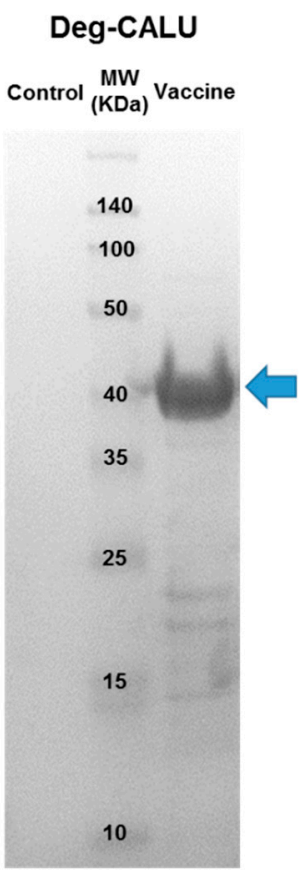

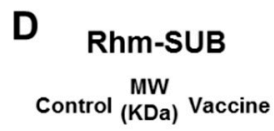

Control (KDa) Vaccine

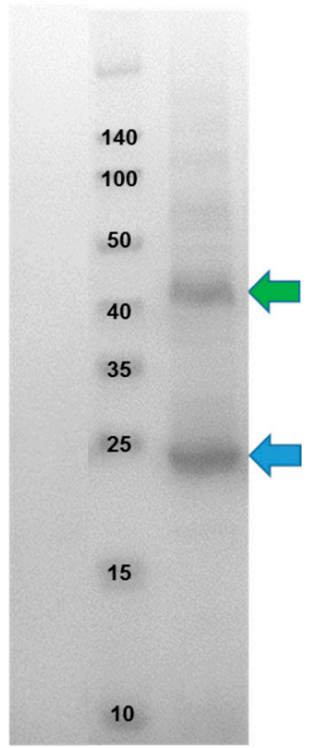

Figure 7. Characterization of the immune response against recombinant vaccines. Antibody levels were determined by ELISA in vaccinated and control hens against Deg-CALU (A) and Rhm-SUB (B). Serum samples were collected before each vaccination (arrows) (D0 and D14), during mite infestation (D28) and at the end of the experiment. Antibody titers are represented as the average OD450nm \pm SD of three replicates and compared between vaccinated and control groups by Mann-Whitney U test $\left.{ }^{*} p<0.05\right)$. Serum samples for control group are pooled. Characterisation by Western Blot of anti-Deg-CALU IgY (C) and anti-Rhm-SUB (D). Ten $\mu \mathrm{g}$ of protein were loaded per well in a SDS-12\% polyacrylamide gel. The gel was used for Western Blot analysis (WB) using sera of vaccinated and control hens collected on day 28 after V1. The position of the recombinant proteins is indicated with blue arrows. The green arrow indicates the potential presence of Subolesin dimers. 

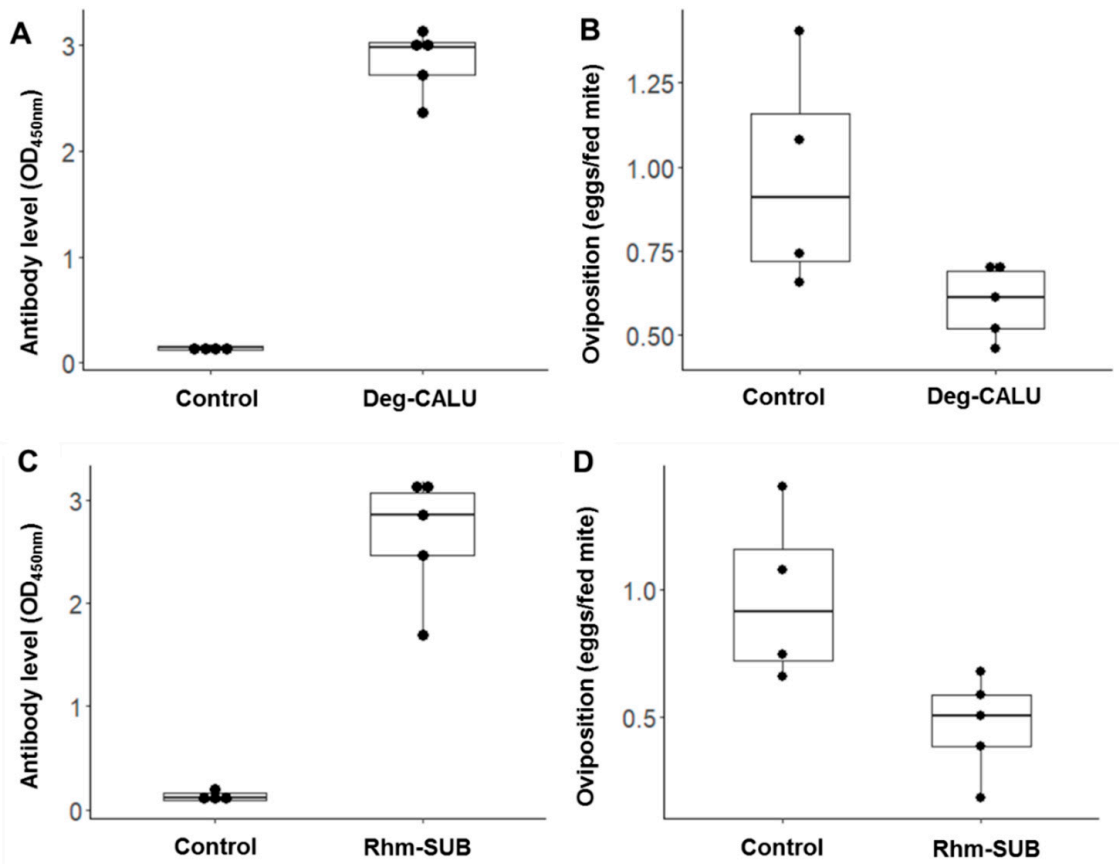

Figure 8. Comparison of antibody level and oviposition amongst groups. Antibody levels at the moment of infestation were determined by ELISA in vaccinated and control hens against Deg-CALU (A) and Rhm-SUB (C). Antibody titers are determined as the average OD450nm of three replicates and compared between vaccinated and control groups by Mann-Whitney $U$ test $\left({ }^{*} p<0.05\right)$. Oviposition of the Deg-CALU group (B) and Rhm-SUB (D) are shown to be compared with the control group. Oviposition is calculated as eggs laid/number fed adult viable female mites counted at day 7 of monitorization. Effect in oviposition is statistically significant in both groups (GLMM, $p<0.01$ ).

\subsection{Vaccines Protective Effect}

Vaccines against ectoparasites are not designed to prevent infestations but to reduce arthropod populations by affecting their feeding, reproduction and development after feeding on immunized animals and ingesting specific antibodies which interact with the target protein function [38].

Vaccination affected the mite reproduction in two ways: reducing the proportion of fed mites laying eggs and reducing the number of eggs laid per fed mite (Table 2). The number of female fed mites which laid eggs was reduced by a $35 \%$ in the Deg-CALU group (mean $=17 \pm 4 \%$ ) and a $44 \%$ in the Rhm-SUB group (mean $=14.9 \pm 5 \%$ ) when compared to control group (mean $=26.7 \pm 8 \%$ ) (Table 2). In a pair-wise comparison between treatment groups and control group the difference in the means were statiscally significant when performed a Student's T-test with equal variance for Rhm-SUB and the control group $(t=-2.66, \mathrm{df}=8, p=0.03)$; and a tendency was observed when the test was performed between Deg-CALU and control $(t=-2.331, \mathrm{df}=7, p=0.05)$. Mites fed on hens vaccinated with Deg-CALU showed average oviposition of $0.62( \pm 0.1)$ eggs per viable fed female (Figure $8 \mathrm{~B})$ mite while for those vaccinated with Rhm-SUB the average oviposition was $0.48( \pm 0.2)$ eggs per fed viable female mite (Figure $8 \mathrm{D}$ ), giving a reduction of $38 \%$ and $52 \%$, respectively, when compared to the control group (Table 2). The effect on the oviposition was statistically significant (GLMM, F $=7.518$, $p=0.001)$ with the Deg-CALU group $(\mathrm{F}=-0.552, \mathrm{SE}=0.172, p=0.001)$ and the Rhm-SUB group $(\mathrm{F}=-0.633, \mathrm{SE}=0.183, p=0.001)$. Calumenin is a well-conserved secreted protein in mammals $[39,40]$ which may be involved in homeostatic and pathologic processes by regulation of $\mathrm{Ca} 2+$ transportation and could participate in signal transduction [41]. In invertebrates, it has been found in the digestive tract of several parasitic nematodes [42,43]. Calumenin has been revealed to be necessary for fertility, locomotion and body size in Caenorhabditis elegans [42]. Vaccination with Subolesin and Akirin have also shown deleterious effects on the reproduction in multiple ectoparasite species [37]. This is the first study in which the reproductive effects of vaccination with calumenin are shown. 
Table 2. Summary of Adult Female PRM Feeding Rates and Vaccine Efficacy.

\begin{tabular}{|c|c|c|c|c|c|c|c|c|c|c|c|c|c|c|c|c|}
\hline Antigen & Hen & Fed Mites & $\begin{array}{l}\text { Unfed } \\
\text { Mites }\end{array}$ & Total & $\%$ Fed & $\begin{array}{l}\text { Average } \\
\text { Feeding } \\
\pm \text { SD } \\
\end{array}$ & $\begin{array}{l}\% \\
\text { Reduction }\end{array}$ & $\begin{array}{l}\text { Laying } \\
\text { Mites }\end{array}$ & $\begin{array}{l}\text { Total } \\
\text { Viable } \\
\text { Mites } \\
\end{array}$ & \% Laying & $\begin{array}{l}\text { Average } \\
\text { Laying } \\
\pm \text { SD } \\
\end{array}$ & $\begin{array}{l}\% \\
\text { Reduction }\end{array}$ & Egg & $\begin{array}{l}\text { Eggs/Fed } \\
\text { Mite }\end{array}$ & $\begin{array}{l}\text { Average } \\
\text { Oviposition } \\
\pm \text { SD } \\
\end{array}$ & $\begin{array}{l}\% \\
\text { Reduction }\end{array}$ \\
\hline \multirow{5}{*}{ Rhm-SUB } & 1 & 154 & 91 & 245 & 62.9 & \multirow[t]{5}{*}{$60 \pm 7$} & \multirow[t]{5}{*}{15} & 20 & 135 & 15 & \multirow[t]{5}{*}{$15 \pm 5$} & \multirow[t]{5}{*}{$44^{*}$} & 59 & 0.44 & \multirow[t]{5}{*}{$0.48 \pm 0.2$} & \multirow[t]{5}{*}{$52 *$} \\
\hline & 2 & 126 & 60 & 186 & 67.7 & & & 25 & 125 & 20 & & & 85 & 0.68 & & \\
\hline & 3 & 82 & 82 & 164 & 50.0 & & & 5 & 80 & 6 & & & 15 & 0.19 & & \\
\hline & 4 & 153 & 115 & 268 & 57.1 & & & 26 & 148 & 18 & & & 79 & 0.60 & & \\
\hline & 5 & 178 & 112 & 290 & 61.4 & & & 27 & 171 & 16 & & & 87 & 0.51 & & \\
\hline \multirow{5}{*}{ Deg-CALU } & 6 & 230 & 84 & 314 & 73.2 & \multirow[t]{5}{*}{$65 \pm 15$} & 7 & 29 & 215 & 13 & \multirow[t]{5}{*}{$17 \pm 4$} & $35^{*}$ & 106 & 0.49 & \multirow[t]{5}{*}{$0.62 \pm 0.1$} & \multirow[t]{5}{*}{$38 *$} \\
\hline & 7 & 253 & 84 & 337 & 75.1 & & & 40 & 240 & 17 & & & 155 & 0.65 & & \\
\hline & 8 & 194 & 78 & 272 & 71.3 & & & 29 & 186 & 16 & & & 99 & 0.53 & & \\
\hline & 9 & 66 & 108 & 174 & 37.9 & & & 15 & 65 & 23 & & & 47 & 0.72 & & \\
\hline & 10 & 135 & 62 & 197 & 68.5 & & & 23 & 128 & 18 & & & 93 & 0.73 & & \\
\hline \multirow{4}{*}{ Control } & 16 & 202 & 45 & 247 & 81.8 & \multirow[t]{4}{*}{$70 \pm 12$} & & 73 & 190 & 38 & \multirow{4}{*}{\multicolumn{2}{|c|}{$27 \pm 8$}} & 281 & 1.48 & \multirow[t]{4}{*}{$1.01 \pm 0.4$} & \\
\hline & 17 & 158 & 130 & 288 & 54.9 & & & 29 & 147 & 20 & & & 103 & 0.70 & & \\
\hline & 18 & 210 & 59 & 269 & 78.1 & & & 48 & 204 & 24 & & & 156 & 0.76 & & \\
\hline & 20 & 180 & 93 & 273 & 65.9 & & & 44 & 175 & 25 & & & 194 & 1.11 & & \\
\hline
\end{tabular}

Data shown are a compilation from the three assays. Feeding rates were scored on day 1 of the assay, immediately following removal of the feeding devices from the hens. Reproduction effects were scored on day 7. Data were analyzed statistically to compare results between mites fed on vaccinated and control hens by GLMM. Statistically significant results $(p<0.05)$ are marked $\left(^{*}\right)$. Fed mites $=$ total of fully engorged adult female mites recovered. Unfed mites $=$ total of unfed adult female mites counted after $3 \mathrm{~h}$ placed on the hen. $\%$ Fed reduction $=-[1-$ (Average Feeding vaccinated group/Average Feeding Control) $] \times 100$. (Student t-test, ${ }^{*} p \leq 0.05$ ). Laying mites $=$ total of mites that had laid eggs at day 7 . Total viable mites $=$ total of mites which that did not die or escaped at day 7 of monitoring. \% Reduction in laying mites $=-[1-$ (Average Laying mites vaccinated group/Average Laying mites control group)] $\times 100$. Eggs $=$ total accumulative count of eggs laid at day 7 . Oviposition $=$ eggs laid/number fed adult viable female mites. \% Oviposition reduction $=-[1-($ Average Oviposition vaccinated group /Average Oviposition Control)] × 100. (GLMM, * $p<0.05)$. 
Vaccination did not affect mite feeding rates, mortality, egg hatchability and larval development. No significant effects on feeding rates and mite mortality have been observed with the Deg-CALU and Rhm-SUB vaccinations (Table 2). The feeding rates observed in this study are similar to the obtained rates observed in previous works that used the on-hen feeding device [34,35]. Subolesin has reduced the number of engorged female ticks fed on vaccinated cattle [44]. In a previous work [22], a mosquito ortholog of the tick Subolesin was used to vaccinate hens showing a $35.1 \%$ increased mite mortality during in-vitro feeding tests. However, in-vitro feeding tests have shown a high background mite mortality in previous studies [16]. The use of anticoagulants and the high temperatures needed for encouraging mite feeding poses variable background mortality in the in vitro test [35]. The on-hen feeding assay allows a more physiological feeding of the mites, as they directly fed from the skin of the bird, and feeding on untreated (no heparin) blood.

\section{Conclusions}

The results obtained in this study provide the first description of the proteomes of different development stages and feeding status in the PRM. Based on this description, we selected a new vaccine candidate and evaluated its efficiency. The reduction in the oviposition observed in hens vaccinated with Deg-CALU and Rhm-SUB supports their consideration as protective antigens for the control of PRM.

Supplementary Materials: The following are available online at http://www.mdpi.com/2076-393X/7/4/190/s1, Table S1: Proteomics Results.

Author Contributions: Conceptualization: M.V., K.B. and J.d.1.F.; Data curation: J.F.L.-B., R.T.-O., C.S. and M.V.; Formal analysis: J.F.L.-B., R.T.-O. and M.V.; Funding acquisition: M.B., U.H., J.d.l.F. and M.V.; Investigation: J.F.L.-B., M.C., F.M.M.-L., L.M.-H., D.R.G.P., F.N., K.B., R.D.F. and M.V.; Methodology: M.V., K.B. and J.d.l.F.; Project administration: M.V. and J.d.l.F.; Resources: O.S., R.D.F., C.S., M.C., L.M.-H., D.R.G.P., F.N., K.B., A.J.N., U.H. and M.V.; Software: J.F.L.-B., R.T.-O. and M.V.; Supervision: A.J.N., M.V. and J.d.1.F.; Validation: K.B., M.V. and J.d.1.F.; Visualization: J.F.L.-B., M.V. and J.d.1.F.; Writing-original draft: J.F.L.-B., M.V. and J.d.l.F.; Writing-review \& editing: all authors.

Funding: This work was partially supported by the European Cooperation in Science and Technology (COST), Improving current understanding and research for sustainable control of the poultry red mite Dermanyssus gallinae - COREMI project (Action FA1404). JFLB was supported by Ministerio de Ciencia, Innovación y Universidades (Spain), Doctorado Industrial contract (DI-14-06917) and Sabiotec SA. MV was supported by the University of Castilla- La Mancha (Spain).

Conflicts of Interest: J.F.L.-B. is funded by Sabiotec S.A. (Ciudad Real, Spain) but the funders had no role in the design of the study, in the collection, analyses, or interpretation of data, in the writing of the manuscript, or in the decision to publish the results.

\section{References}

1. Chauve, C. The poultry red mite Dermanyssus gallinae (De Geer, 1778): Current situation and future prospects for control. Vet. Parasitol. 1998, 79, 239-245. [CrossRef]

2. Sparagano, O.A.E.; George, D.R.; Harrington, D.W.J.; Giangaspero, A. Significance and Control of the Poultry Red Mite, Dermanyssus gallinae. Annu. Rev. Entomol. 2014, 59, 447-466. [CrossRef] [PubMed]

3. Maurer, V.; Bieri, M.; Foelsch, D.W. Das Suchverhalten von Dermanyssus gallinae in Huhnerstallen. Host-finding of Dermanyssus gallinae in poultry-houses. Eur. Poult. Sci. 1988, 52, 209-215.

4. Koenraadt, C.J.M.; Dicke, M. The role of volatiles in aggregation and host-seeking of the haematophagous poultry red mite Dermanyssus gallinae (Acari: Dermanyssidae). Exp. Appl. Acarol. 2010, 50, 191-199. [CrossRef]

5. Roy, L.; Chauve, C.M.; Buronfosse, T. Contrasted ecological repartition of the Northern Fowl Mite Ornithonyssus sylviarum (Mesostigmata: Macronyssidae) and the Chicken Red Mite Dermanyssus gallinae (Mesostigmata: Dermanyssidae). Acarologia 2010, 50, 207-219. [CrossRef]

6. Kilpinen, O. Activation of the poultry red mite, Dermanyssus gallinae (Acari: Dermanyssidae), by increasing temperatures. Exp. Appl. Acarol. 2001, 25, 859-867. [CrossRef] 
7. Cosoroaba, I. Massive Dermanyssus gallinae invasion in battery-husbandry raised fowls. Rev. De Méd. Vét. 2001, 152, 89-96.

8. Kilpinen, O.; Roepstorff, A.; Permin, A.; Nørgaard-Nielsen, G.; Lawson, L.G.; Simonsen, H.B. Influence of Dermanyssus gallinae and infections on behaviour and health of laying hens (Gallus gallus domesticus). Br. Poult. Sci. 2005, 46, 26-34. [CrossRef]

9. Sigognault Flochlay, A.; Thomas, E.; Sparagano, O.A.E. Poultry red mite (Dermanyssus gallinae) infestation: A broad impact parasitological disease that still remains a significant challenge for the egg-laying industry in Europe. Parasites Vectors 2017, 10, 357. [CrossRef]

10. Sommer, D.; Heffels-Redmann, U.; Köhler, K.; Lierz, M.; Kaleta, E.F. Role of the poultry red mite (Dermanyssus gallinae) in the transmission of avian influenza A virus. Tierarztl. Prax. Ausg. G Grosstiere Nutztiere 2016, 44, 26-33. [CrossRef]

11. Valiente Moro, C.; De Luna, C.J.; Tod, A.; Guy, J.H.; Sparagano, O.A.E.; Zenner, L. The poultry red mite (Dermanyssus gallinae): A potential vector of pathogenic agents. Exp. Appl. Acarol. 2009, 48, 93-104. [CrossRef] [PubMed]

12. Mul, M.F.; Van Niekerk, T.; Chirico, J.; Maurer, V.; Kilpinen, O.; Sparagano, O.; Thind, B.; Zoons, J.; Moore, D.; Bell, B.; et al. Control methods for Dermanyssus gallinae in systems for laying hens: Results of an international seminar. Worlds Poult. Sci. J. 2009, 65, 589-600. [CrossRef]

13. Van Emous, R.A. Verwachtte Schade Bloedluis 21 Miljoen Euro. Available online: https://www.pluimveeweb. nl/artikelen/2017/01/schade-bloedluis-21-miljoen-euro/ (accessed on 5 January 2018).

14. Marangi, M.; Cafiero, M.A.; Capelli, G.; Camarda, A.; Sparagano, O.A.; Giangaspero, A. Evaluation of the poultry red mite, Dermanyssus gallinae (Acari: Dermanyssidae) susceptibility to some acaricides in field populations from Italy. Exp. Appl. Acarol. 2009, 48, 11-18. [CrossRef] [PubMed]

15. De la Fuente, J.; Moreno-Cid, J.A.; Canales, M.; Villar, M.; de la Lastra, J.M.; Kocan, K.M.; Galindo, R.C.; Almazán, C.; Blouin, E.F. Targeting arthropod Subolesin/akirin for the development of a universal vaccine for control of vector infestations and pathogen transmission. Vet. Parasitol. 2011, 181, 17-22. [CrossRef] [PubMed]

16. Bartley, K.; Wright, H.W.; Huntley, J.F.; Manson, E.D.; Inglis, N.F.; McLean, K.; Nath, M.; Bartley, Y.; Nisbet, A.J. Identification and evaluation of vaccine candidate antigens from the poultry red mite (Dermanyssus gallinae). Int. J. Parasitol. 2015, 45, 819-830. [CrossRef] [PubMed]

17. De la Fuente, J.; Almazán, C.; Canales, M.; Pérez de la Lastra, J.M.; Kocan, K.M.; Willadsen, P. A ten-year review of commercial vaccine performance for control of tick infestations on cattle. Anim. Health Res. Rev. 2007, 8, 23-28. [CrossRef]

18. Bartley, K.; Huntley, J.F.; Wright, H.W.; Nath, M.; Nisbet, A.J. Assessment of cathepsin D and L-like proteinases of poultry red mite, Dermanyssus gallinae (De Geer), as potential vaccine antigens. Parasitology 2012, 139, 755-765. [CrossRef]

19. Makert, G.R.; Vorbrüggen, S.; Krautwald-Junghanns, M.E.; Voss, M.; Sohn, K.; Buschmann, T.; Ulbert, S. A method to identify protein antigens of Dermanyssus gallinae for the protection of birds from poultry mites. Parasitol. Res. 2016, 115, 2705-2713. [CrossRef]

20. Schicht, S.; Qi, W.; Poveda, L.; Strube, C. Whole transcriptome analysis of the poultry red mite Dermanyssus gallinae (De Geer, 1778). Parasitology 2014, 141, 336-346. [CrossRef]

21. Burgess, S.T.G.; Bartley, K.; Nunn, F.; Wright, H.W.; Hughes, M.; Gemmell, M.; Haldenby, S.; Paterson, S.; Rombauts, S.; Tomley, F.M.; et al. Draft Genome Assembly of the Poultry Red Mite, Dermanyssus gallinae. Microbiol. Resour. Announc. 2018, 7, e01221-18. [CrossRef]

22. Harrington, D.; Canales, M.; de la Fuente, J.; de Luna, C.; Robinson, K.; Guy, J.; Sparagano, O. Immunisation with recombinant proteins Subolesin and Bm86 for the control of Dermanyssus gallinae in poultry. Vaccine 2009, 27, 4056-4063. [CrossRef] [PubMed]

23. Lima-Barbero, J.F.; Díaz-Sanchez, S.; Sparagano, O.; Finn, R.D.; de la Fuente, J.; Villar, M. Metaproteomics characterization of the alphaproteobacteria microbiome in different developmental and feeding stages of the poultry red mite Dermanyssus gallinae (De Geer, 1778). Avian Pathol. 2019, 1, 179. [CrossRef] [PubMed]

24. Villar, M.; Popara, M.; Mangold, A.J.; de la Fuente, J. Comparative proteomics for the characterization of the most relevant Amblyomma tick species as vectors of zoonotic pathogens worldwide. J. Proteom. 2014, 105, 204-216. [CrossRef] [PubMed]

25. Shevchenko, A.; Tomas, H.; Havli, J.; Olsen, J.V.; Mann, M. In-gel digestion for mass spectrometric characterization of proteins and proteomes. Nat. Protoc. 2006, 1, 2856-2860. [CrossRef] [PubMed] 
26. Schicht, S.; Qi, W.; Poveda, L.; Strube, C. The predicted secretome and transmembranome of the poultry red mite Dermanyssus gallinae. Parasites Vectors 2013, 6, 259. [CrossRef] [PubMed]

27. Heberle, H.; Meirelles, G.V.; da Silva, F.R.; Telles, G.P.; Minghim, R. InteractiVenn: A web-based tool for the analysis of sets through Venn diagrams. BMC Bioinform. 2015, 16, 169. [CrossRef]

28. R Core Team. R: A Language and Environment for Statistical Computing; R Foundation for Statistical Computing: Vienna, Austria, 2016; Available online: http://www.R-project.org (accessed on 10 September 2018).

29. Wright, H.W.; Bartley, K.; Huntley, J.F.; Nisbet, A.J. Characterisation of tropomyosin and paramyosin as vaccine candidate molecules for the poultry red mite, Dermanyssus gallinae. Parasites Vectors 2016, 9, 544. [CrossRef]

30. Bartley, K.; Nisbet, A.J.; Offer, J.E.; Sparks, N.H.; Wright, H.W.; Huntley, J.F. Histamine Release Factor from Dermanyssus gallinae (De Geer): Characterization and in vitro assessment as a protective antigen. Int. J. Parasitol. 2009, 39, 447-456. [CrossRef]

31. Almazán, C.; Lagunes, R.; Villar, M.; Canales, M.; Rosario-Cruz, R.; Jongejan, F.; de la Fuente, J. Identification and characterization of Rhipicephalus (Boophilus) microplus candidate protective antigens for the control of cattle tick infestations. Parasitol. Res. 2010, 106, 471-479. [CrossRef]

32. Moreno-Cid, J.A.; Pérez de la Lastra, J.M.; Villar, M.; Jiménez, M.; Pinal, R.; Estrada-Peña, A.; Molina, R.; Lucientes, J.; Gortázar, C.; de la Fuente, J. Control of multiple arthropod vector infestations with Subolesin/akirin vaccines. Vaccine 2013, 31, 1187-1196. [CrossRef]

33. Merino, O.; Antunes, S.; Mosqueda, J.; Moreno-Cid, J.A.; Pérez de la Lastra, J.M.; Rosario-Cruz, R.; Rodríguez, S.; Domingos, A.; de la Fuente, J. Vaccination with proteins involved in tick-pathogen interactions reduces vector infestations and pathogen infection. Vaccine 2013, 31, 5889-5896. [CrossRef] [PubMed]

34. Price, D.R.; Küster, T.; Øines, Ø.; Margaret Oliver, E.; Bartley, K.; Nunn, F.; Lima-Barbero, J.F.; Pritchard, J.; Karp-Tatham, E.; Hauge, H.; et al. Evaluation of vaccine delivery systems for inducing long-lived antibody responses to Dermanyssus gallinae. Avian Pathol. 2019. [CrossRef] [PubMed]

35. Nunn, F.; Bartley, K.; Palarea-Albaladejo, J.; Innocent, G.T.; Turnbull, F.; Wright, H.W.; Nisbet, A.J. A novel, high-welfare methodology for evaluating poultry red mite interventions in vivo. Vet. Parasitol. 2019, 267, 42-46. [CrossRef] [PubMed]

36. Bartley, K.; Turnbull, F.; Wright, H.W.; Huntley, J.F.; Palarea-Albaladejo, J.; Nath, M.; Nisbet, A.J. Field evaluation of poultry red mite (Dermanyssus gallinae) native and recombinant prototype vaccines. Vet. Parasitol. 2017, 244, 25-34. [CrossRef] [PubMed]

37. Artigas-Jerónimo, S.; Villar, M.; Cabezas-Cruz, A.; Valdés, J.J.; Estrada-Peña, A.; Alberdi, P.; de la Fuente, J. Functional evolution of Subolesin/Akirin. Front. Physiol. 2018, 9, 1612. [CrossRef] [PubMed]

38. De la Fuente, J.; Contreras, M. Tick vaccines: Current status and future directions. Expert Rev. Vaccines 2015, 14, 1367-1376. [CrossRef]

39. Jung, D.H.; Kim, D.H. Characterization of isoforms and genomic organization of mouse calumenin. Gene 2004, 327, 185-194. [CrossRef]

40. Vorum, H.; Jacobsen, C.; Honoré, B. Calumenin interacts with serum amyloid P component. FEBS Lett. 2000, 465, 129-134. [CrossRef]

41. Honoré, B. The rapidly expanding CREC protein family: Members, localization, function, and role in disease. BioEssays 2009, 31, 262-277. [CrossRef]

42. Cho, J.H.; Song, H.; Singaravelu, G.; Sung, H.; Oh, W.; Kwon, S.; Kim, D.H.; Ahnn, J. Pleiotropic roles of calumenin (calu-1), a calcium-binding ER luminal protein, in Caenorhabditis elegans. FEBS Lett. 2009, 583, 3050-3056. [CrossRef]

43. Figueiredo, B.C.; Ricci, N.D.; de Assis, N.R.G.; de Morais, S.B.; Fonseca, C.T.; Oliveira, S.C. Kicking in the guts: Schistosoma mansoni digestive tract proteins are potential candidates for vaccine development. Front. Immunol. 2015, 6, 22. [CrossRef] [PubMed]

44. Merino, O.; Almazán, C.; Canales, M.; Villar, M.; Moreno-Cid, J.A.; Estrada-Peña, A.; Kocan, K.M.; de la Fuente, J. Control of Rhipicephalus (Boophilus) microplus infestations by the combination of Subolesin vaccination and tick autocidal control after Subolesin gene knockdown in ticks fed on cattle. Vaccine 2011, 29, 2248-2254. [CrossRef] [PubMed]

(C) 2019 by the authors. Licensee MDPI, Basel, Switzerland. This article is an open access article distributed under the terms and conditions of the Creative Commons Attribution (CC BY) license (http://creativecommons.org/licenses/by/4.0/). 